\title{
PTHR1 Genetic Polymorphisms Are Associated with Osteoporosis among Postmenopausal Arab Women
}

\author{
Saba Abdi $\left(\mathbb{D},{ }^{1}\right.$ Abeer Abdulaziz Almiman, ${ }^{2}$ Mohammed Ghouse Ahmed Ansari $\mathbb{D}^{2}{ }^{2}$ \\ Abdullah M. Alnaami, ${ }^{2}$ Abdul Khader Mohammed, ${ }^{2,3}$ Naji J. Aljohani, ${ }^{2,4}$ Amal Alenad,, \\ Amani Alghamdi $\mathbb{D}^{1,2}$ Majed S. Alokail,, ${ }^{1,2}$ and Nasser M. Al-Daghri $\mathbb{D}^{1,2}$ \\ ${ }^{1}$ Biochemistry Department, College of Science, King Saud University, Riyadh 11451, Saudi Arabia \\ ${ }^{2}$ Chair for Biomarkers of Chronic Diseases, Department of Biochemistry, College of Science, King Saud University, \\ Riyadh 11451, Saudi Arabia \\ ${ }^{3}$ Sharjah Institute for Medical Research, University of Sharjah, Sharjah 27272, UAE \\ ${ }^{4}$ Obesity, Endocrine, And Metabolic Center, King Fahad Medical City, Riyadh 59046, Saudi Arabia
}

Correspondence should be addressed to Nasser M. Al-Daghri; aldaghri2011@gmail.com

Received 15 July 2021; Accepted 13 December 2021; Published 22 December 2021

Academic Editor: Jorge A. Roman Blas

Copyright (c) 2021 Saba Abdi et al. This is an open access article distributed under the Creative Commons Attribution License, which permits unrestricted use, distribution, and reproduction in any medium, provided the original work is properly cited.

The parathyroid hormone 1 receptor (PTHR1) plays a crucial role in calcium homeostasis and bone metabolism. However, its genetic role in regulating bone turnover markers (BTMs) in postmenopausal osteoporosis (PMO) remains unclear. Herein, we explored parathyroid hormone (PTH) and PTHR gene variant susceptibility to osteoporosis and their association with various circulating BTM and inflammatory markers in postmenopausal women of Arab ethnicity. In total, 600 postmenopausal Arab women (300-PMO and 300-control) were genotyped for selected SNPs in PTH (rs1459015, rs307253, rs6054, rs307247, rs10500783 and rs10500784), PTHR1 (rs6442037, rs1138518, and rs724449 SNPs) and PTHR2 (rs9288393, rs10497900, and rs897083). Anthropometrics, BTMs, and inflammatory markers were measured. Bone mineral density (BMD) was measured at the lumbar spine L1-L4 and the femoral neck using dual-energy X-ray absorptiometry (DXA). PTHR1 rs1138518 genotype C/ $\mathrm{T}$ was found to be a significant risk factor for PMO ( $\mathrm{OR}=1.49,95 \% \mathrm{CI} 1.0-2.1, P=0.03)$. The genotypes $\mathrm{C} / \mathrm{T}$ and $\mathrm{T} / \mathrm{T}$ of PTHR1 rs1138518 were associated with 25-hydroxy-vitamin D $(25(\mathrm{OH}) \mathrm{D})$ regulation. In the PMO group, carriers of the C/T genotype had significantly lower 25(OH)D levels than carriers of the same genotypes in the control group (59.9 (36.7-92.4) $\mathrm{nmol} / \mathrm{l}$ and $66.4(43.5-87.8) \mathrm{nmol} / \mathrm{l}$, respectively; $P=0.048$ ]. Our study concludes that the PTHR1 rs1138518 genotype could be a potential risk factor for osteoporosis and 25(OH)D regulation in Arab women with PMO.

\section{Introduction}

Osteoporosis is one of the most common chronic conditions affecting the elderly population and a significant public health concern. Worldwide, the age and hormonal changes related to postmenopausal osteoporosis (PMO) affect more than $50 \%$ of women aged fifty and above [1-3]. In Saudi Arabia, the prevalence of osteoporosis among individual's $\geq 50$ years is $44.5 \%$ in females and $33.2 \%$ in males [4-6].

Parathyroid hormone (PTH) plays a significant physiological role in maintaining calcium $\left(\mathrm{Ca}^{2+}\right)$ and phosphate $\left(\mathrm{P}_{\mathrm{i}}\right)$ homeostasis in the body [7]. In response to low circulat- ing $\mathrm{Ca}^{2+}$ levels, active PTH directly stimulates the differentiation of bone-forming osteoblasts into bone-resorbing osteoclasts, leading to bone resorption and $\mathrm{Ca}^{2+}[8]$. Two types of receptors for PTH have been recognized. Parathyroid hormone receptor type 1 (PTHR1) is activated by $\mathrm{PTH}$ and PTH-related protein (PTHrP). In contrast, parathyroid hormone receptor type 2 (PTHR2) is activated by PTH but not PTHrP $[9,10]$.

The gene for PTHR1 is located in exon 14 of chromosome 3 and is predominantly expressed in osteocytes and osteoblasts [11]. PTHR1 regulates $\mathrm{Ca}^{2+}$ concentration in blood [12], and its abnormal expression corresponds to 
several metabolic disturbances and critical bone dimorphisms [13].

PTH ligation to PTHR initiates several intracellular signaling pathways [14] that may be G-protein-dependent or independent [15]. A study of PTHR ligands modifications could help understand PTHR function and improve therapeutic options for disorders caused by the defective PTHR1 signaling pathways [9]. Receptor-associated diseases such as hypoparathyroidism and osteoporosis are the most common disorders approved to benefit PTHR1-based therapies [9].

Previously, our group investigated the association between PTH SNPs and the serum levels of 25-hydroxyvitamin D $(25(\mathrm{OH}) \mathrm{D})$ and showed that PTH SNP rs1459015 was associated with higher $25(\mathrm{OH}) \mathrm{D}$ levels in several populations [16]. We intend to expand our knowledge of the genetic polymorphisms in PTH and PTHRs among postmenopausal Arab women with osteoporosis from this preliminary evidence. Therefore, this study is aimed at investigating the role of genetic polymorphisms in PTH and PTHRs in regulating bone turnover markers and inflammation markers in PMO patients. A casecontrol study was conducted with data from 300 PMO patients and 300 controls of Arab ethnicity. This study was designed to examine the association of PMO with selected SNPs in PTH (rs6254, rs1459015, rs307253, rs307247, rs10500783, and rs10500784), PTHR1 (rs6442037, rs1138518, and rs724449) and PTHR2 (rs10497900, rs 897083, and rs9288393).

\section{Materials and Methods}

2.1. Study Subjects. This case-control study was conducted according to the guidelines of the Declaration of Helsinki and approved by the Ethics Committee of The College of Science, King Saud University, Riyadh, Kingdom of Saudi Arabia (KSA), No. 8/25/36516, and all methods were carried out in accordance with relevant guidelines and regulations. Clinical information of 600 postmenopausal women was collected from the Osteoporosis Registry Database of the Chair for Biomarkers of Chronic Disease (CBCD) at KSU, Riyadh, Saudi Arabia $[5,6,17]$. Participants were recruited from the outpatient clinics of the departments of orthopaedics at King Khalid University Hospital (KKUH), King Fahad Medical City (KFMC), and King Salman Hospital, Riyadh, Saudi Arabia. Written informed consent was obtained from all study subjects prior to their inclusion in the study.

2.2. Clinical and Anthropometric Measurements. All information was collected from the registry database. Exclusion criteria were as follows: the presence of any systemic or metabolic disease other than osteoporosis; a food disorder, antacids, steroids, or cortisone; hormone replacement therapy; the use of calcium or a multivitamins supplement; or the use of any drugs that could affect PTH levels. Demographic data included age, sex, and medical history. Anthropometry included height and weight measurements. Body mass index (BMI) was calculated according to the standard equation $\left(\mathrm{kg} / \mathrm{m}^{2}\right)$. Bone mineral density (BMD) was measured at the lumbar spine L1-L4 and the femoral neck using dualenergy X-ray absorptiometry (DXA). Diagnosis of osteoporosis (femoral neck $T$-score $\leq-2.5 \mathrm{SD}$ from reference mean of young adult female) was based on the national and regional guidelines for Saudi Arabia and Middle East, respectively $[18,19]$.

2.3. Biochemical Assessment. Fasting blood samples were collected from participants and centrifuged immediately. Serum samples were collected and transported directly to $\mathrm{CBCD}$ for storage at $-80^{\circ} \mathrm{C}$ until further analysis. Electrochemiluminescence immunoassays were used to evaluate the levels of total 25(OH)D, N-MID osteocalcin, and $\beta$-crosslaps $(\beta$-CTx) using Cobas e411(Roche Diagnostics, Germany). The intra- and interassay CVs were $4.2 \%$ and $6 \%$ for $25(\mathrm{OH}) \mathrm{D}, 1.28 \%$ and $2.5 \%$ for osteocalcin, and $2.4 \%$ and $4.2 \%$ for the $\beta$-CTx. Serum intact PTH, osteoprotegerin $(\mathrm{OPG})$, osteopontin (OPN), and receptor activator of nuclear factor- $\kappa$ B ligand (RANKL) levels were measured using multiplex assay kits (Millipore Corporation, Billerica, MA, USA.) as measured previously [20]. The intra- and interassay for intact PTH, OPG, and OPN were $10 \%$ and $15 \%$, and for RANKL, $5 \%$ and $6 \%$. All samples were measured in duplicates, and the mean was recorded. Interleukin-4 (IL-4) and transforming growth factor $\beta$ (TGF- $\beta$ ) were measured using enzyme-linked immunosorbent assay (ELISA) kits (R\&D Systems, Minneapolis, MN, USA). The intra- and interassay CVs were $2.4 \%$ and $8.2 \%$ for IL- 4 and $4.7 \%$ and $5.2 \%$ for TGF- $\beta$, respectively.

2.4. SNPs Analysis. DNA was extracted from whole blood using Prep DNA mini kits (Qiagen, Hilden, Germany) following the manufacturer's instructions. DNA concentration was measured using an ND-1000 Nanodrop spectrophotometer (Thermo Scientific, UK). SNPs from PTH (rs6254, rs1459015, rs307253, rs307247, rs10500783, and rs10500784), PTHR1 (rs6442037, rs1138518, and rs724449) and PTHR2 (rs9288393, rs10497900, and rs897083) were selected for genotyping. Genotyping was performed using TaqMan SNP genotyping assay kits for the 12 candidates. An allelic discrimination real-time PCR was used for SNP evaluation. The target sequence was amplified using $30 \mathrm{ng}$ DNA in 96-well PCR plates and a Bio-Rad CFX96 RealTime PCR Detection System (Bio-Rad, Milan, Italy). Random samples were genotyped in triplicates for validation. Genotyping cluster plots were reviewed manually, and three SNPs (rs6254, rs10497900, and rs897083) showed poor cluster separation; hence, they were excluded from the data set before further analysis.

2.5. Statistical Analysis. Data analysis was carried out using SPSS 21.0 software (IBM, Chicago, IL, USA). Outcome measures were presented as mean \pm standard deviation for normal variable and median $\left(1^{\text {st }}-3^{\text {rd }}\right)$ quartiles for normal and nonnormal variables. Furthermore, analysis of covariance (ANCOVA) was used to compare groups, adjusted for age and BMI. Associations between genotype frequencies in the control and patients' groups were analyzed using Fisher's 
exact odds ratio (OR) and the corresponding 95\% confidence intervals (CIs). Correlation results presented as coefficients and with a $P$ value at $<0.05$ was considered significant.

\section{Results}

The statistical analysis of the clinical characteristics and biochemical indices of subjects is shown in Table 1. A total of 600 postmenopausal women were included in this study based on their osteoporosis status; 300 women with PMO were selected for the PMO group and 300 women without PMO for the control group (CG).

PMO subjects were significantly older and had lower BMI measurements $(P$ values $<0.001)$ than those in the CG. A significant difference was observed in the menopause status between the subjects of the PMO group and the CG $(P=0.001)$. The percentage of women who experienced menopause for 10 or more years was more significant in the PMO group (45.3\%) than those in CG (17.7\%). The $B M D$ values were measured at the spine, and the femur sites have a high incidence of osteoporosis. BMD values were significantly lower $(P<0.001)$ in the PMO group compared to the CG at all sites evaluated (Table 1).

Among the BTMs, only OPG levels were significantly higher in the PMO group $(P=0.037)$. However, after adjusting values for age and BMI, the results were not significant (Table 1). Among the inflammatory markers, only IL-4 and TGF- $\beta$ levels differed significantly $(P=0.01$ and $P=$ 0.048 , respectively) between the PMO group and CG. Although, after adjusting values for age and BMI, no significant difference was detected between circulating levels of IL- 4 between the PMO group and CG; however, it was interesting to observe serum TGF- $\beta$ concentrations were significantly lower in the PMO group when compared to the CG $(P=0.019)$ (Table 1).

The genotypic and allelic distributions of the selected SNPs in PMO subjects and control individuals are shown in Table 2. All PTH SNPs selected for this study are located on chromosome 11. No significant difference was observed in genotype or allele frequency distribution of all tested PTH SNPs between the PMO group and CG. The frequencies of the T/T, C/T, and C/C genotypes of PTH rs 1459015 were $5.9 \%, 17 \%$, and $77.1 \%$ in the CG and $5.6 \%, 19.6 \%$, and $74.8 \%$ in the PMO group, respectively. The genotype frequencies of PTH rs307253 were as follows: $12.5 \%$ in A/ $\mathrm{A}, 38.2 \%$ in $\mathrm{A} / \mathrm{G}$, and $\mathrm{G} / \mathrm{G}$ in $\mathrm{CG}$ and $14 \%, 37.1 \%$, and $40.9 \%$ in the PMO group. The frequencies of PTH rs 307247 genotypes were $10.8 \%, 35.8 \%$, and $38.5 \%$ for A/ $\mathrm{A}, \mathrm{A} / \mathrm{G}$, and $\mathrm{G} / \mathrm{G}$ in the CG compared to $12.6 \%, 31.5 \%$, and $38.5 \%$, respectively, in the $\mathrm{PMO}$ group. The frequencies of the PTH rs10500783 genotypes were $\mathrm{T} / \mathrm{T} 5.6 \%, \mathrm{C} / \mathrm{T}$ $33.7 \%$, and $61.5 \%$ in $\mathrm{C} / \mathrm{C}$ in CG and $\mathrm{T} / \mathrm{T} 5.9 \%, \mathrm{C} / \mathrm{T} 26.6 \%$, and $\mathrm{C} / \mathrm{C} 66.8 \%$ in the PMO group. PTH rs10500784 genotype frequencies in the CG were $5.6 \%$ for $\mathrm{C} / \mathrm{C}$ and $33.7 \%$ for $\mathrm{A} / \mathrm{C}$ and $61.5 \%$ for $\mathrm{A} / \mathrm{A}$ compared to $5.2 \%, 26.2 \%$, and $67.8 \%$ for the same genotypes in the PMO group, respectively. Additionally, OR analysis was conducted to evaluate genotypes in the study populations. No statistical correlation was noted between PTH SNP genotypes and the OR adjusted for age and BMI (Table 2).

The distribution frequencies of the PTHR1 SNP genotypes and alleles are also shown in Table 2. All PTHR1 SNPs included in this study are located on chromosome 3 . The genotypic distributions of 4 PTHRs SNPs (rs6442037, rs1138518, rs724449, and PTHR2 rs9288393) were found to be as follows. The frequency of PTHR1 rs6442037 G/G was $12.2 \%, \mathrm{~A} / \mathrm{G} 30.9 \%$, and $\mathrm{A} / \mathrm{A} 50.7 \%$ in the CG group and $\mathrm{G} / \mathrm{G} 9.1 \%, \mathrm{~A} / \mathrm{G} 34.3 \%$, and $\mathrm{A} / \mathrm{A} 46.5 \%$ in the PMO group. The statistical distributions of PTHR1 rs1138518 T/ $\mathrm{T}, \mathrm{C} / \mathrm{T}$, and $\mathrm{C} / \mathrm{C}$, were $12.8 \%, 35.4 \%$, and $49.3 \%$ in the $\mathrm{CG}$ compared to $12.6 \%, 42 \%$, and $39.2 \%$ in the $\mathrm{PMO}$ group. PTHR1 rs724449 T/T, C/T, and C/C genotypes frequencies were $25 \%, 35.1 \%$, and $27.4 \%$ in the CG and $24.5 \%, 41.6 \%$, and $26.2 \%$ in the PMO group. Interestingly, PTHR1 rs1138518 heterozygote genotype $\mathrm{C} / \mathrm{T}$ was significantly associated with the PMO group $(P=0.03)$, where it was at a higher frequency $(42 \%)$ than in the CG $(35.4 \%)$ with an OR of 1.49 with a $95 \%$ CI (1.04-2.14). No other statistical association was observed between PTHR1 genotypes and the PMO group (Table 2).

The genotypic frequencies of $\mathrm{G} / \mathrm{G}, \mathrm{C} / \mathrm{G}$, and $\mathrm{C} / \mathrm{C}$ of PTHR2 SNP rs9288393, located on chromosome 2, were $10 \%, 36.8 \%$, and $53.5 \%$ in the CG and $10.5 \%, 32.2 \%$, and $58 \%$ in the PMO group. The allelic frequency distribution of all SNPs was not related to any study groups (Table 2).

Associations between PTHR1 rs1138518 genotypes and circulating levels of BTMs were evaluated using comparative analysis methods (Table 3). PTHR1 rs1138518 homozygote $\mathrm{T} / \mathrm{T}$ genotype was significantly associated with increased levels $(P=0.04)$ of $25(\mathrm{OH}) \mathrm{D}$ in the PMO group. In contrast, heterozygote genotype $\mathrm{C} / \mathrm{T}$ was significantly associated with reduced levels $(P=0.048)$ of $25(\mathrm{OH}) \mathrm{D}$ in the PMO group. No association was observed in either study groups between the $\mathrm{T} / \mathrm{T}$ or $\mathrm{C} / \mathrm{T}$ genotype and serum levels of $\mathrm{PTH}, \mathrm{OPG}$, OPN, RANKL, osteocalcin and $\beta$-CTx. Furthermore, the C/C genotype of PTHR1 SNP rs1138518 was not found to be significantly linked to the regulation of any BTMs in this study (Table 3).

Concerning the homozygote $\mathrm{T} / \mathrm{T}$ genotype, there were no statistically significant differences in serum IL-4, IL- $1 \beta$, leptin, and TGF- $\beta$ levels between the PMO group and the CG $(P=0.51, P=0.15, P=0.29$, and $P=0.55)$, respectively. Additionally, the $\mathrm{C} / \mathrm{T}$ genotype was not associated with IL-4, IL- $1 \beta$, leptin, nor with TGF- $\beta$ levels. Inflammatory markers in participants with the $\mathrm{C} / \mathrm{C}$ genotype did not exhibit any relationship to the PMO group. However, there was a modest reduction in IL-4 levels in the PMO group, which showed a trend towards significance $(P=0.064)$ compared to the CG (Table 4).

\section{Discussion}

The complex polygenic nature of osteoporosis demands the use of multiple genetic analyses to understand outcomes. Therefore, a genetic assessment approach using osteoporosis molecular markers is highly desirable to detect the hormonally related form of the disease. To date, the role of PTH and 
TABLE 1: Anthropometric and biochemical characteristics of the subjects according to the study groups.

\begin{tabular}{|c|c|c|c|c|}
\hline Parameters & $\begin{array}{c}C G \\
\mathrm{~N}=300\end{array}$ & $\begin{array}{c}\mathrm{PMO} \\
\mathrm{N}=300\end{array}$ & P-value & P- value* \\
\hline \multicolumn{5}{|l|}{ General characteristics } \\
\hline Age (year) & $53.9 \pm 6.1$ & $57.8 \pm 7.9$ & $<0.001$ & \\
\hline BMI $\left(\mathrm{kg} / \mathrm{m}^{2}\right)$ & $34.3 \pm 5.9$ & $31.5 \pm 6.3$ & $<0.001$ & \\
\hline Menopause status ( $\geq 10$ years) & $50(17.7)$ & $129(45.3)$ & $<0.001$ & 0.001 \\
\hline \multicolumn{5}{|l|}{$T$-score and BMD } \\
\hline$T$-score AP spine \# & $-0.31 \pm 0.83$ & $-2.69 \pm 0.67$ & $<0.001$ & $<0.001$ \\
\hline$T$-score femur & $0.44 \pm 1.0$ & $-1.08 \pm 0.9$ & $<0.001$ & $<0.001$ \\
\hline BMD spine $\left(\mathrm{g} / \mathrm{mm}^{2}\right)$ & $1.15 \pm 0.14$ & $0.85 \pm 0.09$ & $<0.001$ & $<0.001$ \\
\hline BMD femur $\left(\mathrm{g} / \mathrm{mm}^{2}\right)$ & $1.03 \pm 0.12$ & $0.84 \pm 0.12$ & $<0.001$ & $<0.001$ \\
\hline \multicolumn{5}{|l|}{ Bone turnover markers } \\
\hline 25(OH)D (nmol/l) & $61.1(37.8-84.5)$ & $66.3(39.1-93.0)$ & 0.20 & 0.70 \\
\hline PTH $(\mathrm{pg} / \mathrm{ml})$ & $12.31(7.59-21.05)$ & $15.41(7.81-34.98)$ & 0.10 & 0.40 \\
\hline OPG (pg/ml) & $752.1(523.9-995.3)$ & $853.6(617.8-1150.7)$ & 0.037 & 0.43 \\
\hline OPN (ng/ml) & $2.32(1.26-3.36)$ & $2.70(1.46-4.10)$ & 0.11 & 0.57 \\
\hline RANKL (pg/ml) & $33.18(18.51-61.02)$ & $28.88(21.77-48.30)$ & 0.50 & 0.33 \\
\hline$\beta$-CTx $(\mathrm{ng} / \mathrm{ml})$ & $0.07(0.04-0.11)$ & $0.07(0.04-0.11)$ & 0.59 & 0.83 \\
\hline Osteocalcin (ng/ml) & $8.89(3.2-13.13)$ & $9.16(3.45-14.19)$ & 0.58 & 0.72 \\
\hline \multicolumn{5}{|l|}{ Inflammatory markers } \\
\hline \multicolumn{5}{|l|}{ Interleukins } \\
\hline IL-4 (pg/ml) & $7.04(3.92-10.33)$ & $4.47(2.52-9.35)$ & 0.012 & 0.06 \\
\hline $\mathrm{IL}-1 \beta(\mathrm{pg} / \mathrm{ml})$ & $1.72(0.39-2.72)$ & $1.64(0.33-2.69)$ & 0.38 & 0.17 \\
\hline \multicolumn{5}{|l|}{ Adipocytokines } \\
\hline Leptin (ng/ml) & $16.14(7.36-33.1)$ & $20.27(8.3-34.23)$ & 0.32 & 0.15 \\
\hline \multicolumn{5}{|l|}{ Growth factors } \\
\hline TGF- $\beta$ (ng/ml) & $40.26(31.47-52.24)$ & $37.58(18.10-48.56)$ & 0.048 & 0.019 \\
\hline
\end{tabular}

Note: data presented as mean \pm standard deviation for normal variables while the median (quartile 1-quartile 3) presented for nonnormal variables; " nonnormal variables; $P$ value $<0.05$ considered significant, ${ }^{*}$ indicates adjusted $P$ value for age and BMI.

PTHRs in PMO had not been elucidated. To our knowledge, this is the first study investigating the role of polymorphisms in PTH and PTHRs as key genetic markers for bone turnover regulation in postmenopausal Saudi Arabian women.

The current study identified PTHR1 SNP rs1138518 C/T genotype to be associated with $\mathrm{PMO}$ patients. The clinical relevance of PTHR1 rs1138518 in PMO had not been previously reported. To our knowledge, this is the first study to confirm the association between the PTHR1 rs1138518 SNP and PMO. We found a significant difference in the distribution of the rs1138518 genotype among groups. The difference was primarily based on a higher frequency of heterozygote C/T genotype (40.0\%) in patients than the control group $(34.0 \%)$. Our study confirms a previous observation by C. Vilariño-Güell et al. [21], who reported that common variants in PTHR1gene influence BMD in general population. They concluded that the association of PTHR1gene polymorphism on BMD was due to its role in attaining peak bone mass and not due to its effect on bone loss in old age. Similarly, several other previous studies have reported linkage of PTHR1 gene to hip [22] and spine BMD
[23]. Additionally, tetranucleotide repeat (AAAG)n polymorphism in the promoter of PTHR1 gene was found to be associated with greater height but not with hip or spine BMD in young adult Japanese women [24]. A study by Zhang et al. failed to find any significant association between BMD and individual SNPs of PTHR1, yet observed an association between haplotype 13 (AATG) and hip peak BMD $[25,26]$. Overall, these studies indicate PTHR1 gene variants to influence bone strength and hence osteoporosis risk.

Further, we conducted an association analysis to investigate whether rs1138518 in PTHR1 influenced the circulating levels of selected bone turnover markers. In PMO subjects, while the $\mathrm{C} / \mathrm{T}$ genotype was found to be linked with a significant reduction in $25(\mathrm{OH}) \mathrm{D}$, the $\mathrm{T} / \mathrm{T}$ genotype was associated with a significant increase in $25(\mathrm{OH}) \mathrm{D}$ levels. This finding suggests that specific genotypes of PTHR1 rs1138518 may play a role in regulating circulating $25(\mathrm{OH}) \mathrm{D}$ levels. Thus, carriers of $\mathrm{C} / \mathrm{T}$ genotype may be at a greater risk if vitamin $\mathrm{D}$ deficiency and its related diseases such as PMO.

$25(\mathrm{OH}) \mathrm{D}$ and PTH are the two foremost regulators of mineral metabolism and are essential for maintaining bone 
TABLE 2: Genotype and allele frequency distribution of PTH and PTHRs SNPs in the study groups.

\begin{tabular}{|c|c|c|c|c|c|c|c|}
\hline Gene & SNP ID & Chromosome: position & Gen. & $\begin{array}{c}\text { CG } \\
N(\%) \\
\end{array}$ & $\begin{array}{c}\text { PMO } \\
N(\%) \\
\end{array}$ & Adjusted OR (95\% CI) & Adjusted $P$ value \\
\hline & & & $\mathrm{T} / \mathrm{T}$ & $17(5.9)$ & $16(5.6)$ & $0.98(0.48-1.98)$ & 0.9 \\
\hline & & & $\mathrm{C} / \mathrm{T}$ & $49(17.0)$ & $56(19.6)$ & $1.19(0.77-1.82)$ & 0.43 \\
\hline & rs1459015 & $11: 13500728$ & ${ }^{*} \mathrm{C} / \mathrm{C}$ & $222(77.1)$ & $214(74.8)$ & 1 & \\
\hline & & & $\mathrm{T}$ & $83(14.4)$ & $88(15.4)$ & $1.08(0.78-1.49)$ & 0.64 \\
\hline & & & $\mathrm{C}$ & $493(85.6)$ & $484(84.6)$ & 1 & \\
\hline & & & $\mathrm{A} / \mathrm{A}$ & $36(12.5)$ & $40(14.0)$ & $1.05(0.62-1.76)$ & 0.87 \\
\hline & & & $\mathrm{A} / \mathrm{G}$ & $110(38.2)$ & $106(37.1)$ & $0.91(0.62-1.32)$ & 0.60 \\
\hline & rs307253 & $11: 13488070$ & ${ }^{*} \mathrm{G} / \mathrm{G}$ & $110(38.2)$ & $117(40.9)$ & 1 & \\
\hline & & & A & $182(35.5)$ & $186(35.4)$ & $0.99(0.77-1.28)$ & 0.95 \\
\hline & & & G & $330(64.5)$ & $340(64.6)$ & 1 & \\
\hline & & & $\mathrm{A} / \mathrm{A}$ & $31(10.8)$ & $36(12.6)$ & $1.17(0.68-2.1)$ & 0.57 \\
\hline & & & $\mathrm{A} / \mathrm{G}$ & $103(35.8)$ & $90(31.5)$ & $0.88(0.6-1.3)$ & 0.52 \\
\hline \multirow[t]{20}{*}{ PTH } & rs307247 & $11: 13491931$ & $* \mathrm{G} / \mathrm{G}$ & $111(38.5)$ & $110(38.5)$ & 1 & \\
\hline & & & A & $165(33.7)$ & $162(34.3)$ & $1.03(0.79-1.34)$ & 0.83 \\
\hline & & & G & $325(66.3)$ & $310(65.7)$ & 1 & \\
\hline & & & $\mathrm{T} / \mathrm{T}$ & $16(5.6)$ & $17(5.9)$ & $0.98(0.48-2.0)$ & 0.97 \\
\hline & & & $\mathrm{C} / \mathrm{T}$ & $97(33.7)$ & $76(26.6)$ & $0.73(0.51-1.04)$ & 0.08 \\
\hline & rs10500783 & $11: 13552067$ & $* \mathrm{C} / \mathrm{C}$ & $177(61.5)$ & $191(66.8)$ & 1 & \\
\hline & & & $\mathrm{T}$ & $129(22.2)$ & $110(19.4)$ & $0.84(0.63-1.12)$ & 0.23 \\
\hline & & & $\mathrm{C}$ & $451(77.8)$ & $458(80.6)$ & 1 & \\
\hline & & & $\mathrm{CC}$ & $16(5.6)$ & $15(5.2)$ & $0.86(0.41-1.78)$ & 0.68 \\
\hline & & & $\mathrm{A} / \mathrm{C}$ & $97(33.7)$ & $75(26.2)$ & $0.71(0.49-1.01)$ & 0.06 \\
\hline & rs10500784 & $11: 13552278$ & ${ }^{*} \mathrm{AA}$ & $177(61.5)$ & $194(67.8)$ & 1 & \\
\hline & & & A & $129(22.2)$ & $105(18.5)$ & $0.79(0.59-1.06)$ & 0.11 \\
\hline & & & $\mathrm{C}$ & $451(77.8)$ & $463(81.5)$ & 1 & \\
\hline & & & G/G & $35(12.2)$ & $26(9.1)$ & $0.82(0.47-1.43)$ & 0.48 \\
\hline & & & $\mathrm{A} / \mathrm{G}$ & $89(30.9)$ & $98(34.3)$ & $1.21(0.83-1.75)$ & 0.32 \\
\hline & rs6442037 & $3: 46888056$ & $* \mathrm{~A} / \mathrm{A}$ & $146(50.7)$ & $133(46.5)$ & 1 & \\
\hline & & & G & $159(29.4)$ & $150(29.2)$ & $0.99(0.76-1.29)$ & 0.93 \\
\hline & & & A & $381(70.6)$ & $364(70.8)$ & 1 & \\
\hline & & & $\mathrm{T} / \mathrm{T}$ & $37(12.8)$ & $36(12.6)$ & $1.23(0.73-2.10)$ & 0.43 \\
\hline & & & $\mathrm{C} / \mathrm{T}$ & $102(35.4)$ & $120(42.0)$ & $1.49(1.04-2.14)$ & 0.03 \\
\hline \multirow[t]{10}{*}{ PTHR1 } & rs1138518 & $3: 46902784$ & ${ }^{*} \mathrm{C} / \mathrm{C}$ & $142(49.3)$ & $112(39.2)$ & 1 & \\
\hline & & & $\mathrm{T}$ & $176(31.3)$ & $192(35.8)$ & $1.22(0.95-1.57)$ & 0.11 \\
\hline & & & $\mathrm{C}$ & $386(68.7)$ & $344(64.2)$ & 1 & \\
\hline & & & $\mathrm{T} / \mathrm{T}$ & $72(25.0)$ & $70(24.5)$ & $1.02(0.65-1.62)$ & 0.92 \\
\hline & & & $\mathrm{C} / \mathrm{T}$ & $101(35.1)$ & $119(41.6)$ & $1.24(0.82-1.87)$ & 0.30 \\
\hline & rs724449 & $3: 46894191$ & ${ }^{*} \mathrm{C} / \mathrm{C}$ & $79(27.4)$ & $75(26.2)$ & 1 & \\
\hline & & & $\mathrm{T}$ & $245(48.6)$ & $259(49.1)$ & $1.02(0.80-1.30)$ & 0.89 \\
\hline & & & $\mathrm{C}$ & $259(51.4)$ & $269(50.9)$ & 1 & \\
\hline & & & $\mathrm{G} / \mathrm{G}$ & $29(10.1)$ & $30(10.5)$ & $0.96(0.55-1.67)$ & 0.88 \\
\hline & & & $\mathrm{C} / \mathrm{G}$ & $106(36.8)$ & $92(32.2)$ & $0.81(0.56-1.15)$ & 0.23 \\
\hline \multirow[t]{3}{*}{ PTHR2 } & rs9288393 & $2: 208404685$ & ${ }^{*} \mathrm{C} / \mathrm{C}$ & $154(53.5)$ & $166(58.0)$ & 1 & \\
\hline & & & G & $164(28.4)$ & $152(26.4)$ & $0.91(0.70-1.17)$ & 0.45 \\
\hline & & & $\mathrm{C}$ & $414(71.6)$ & $424(73.6)$ & 1 & \\
\hline
\end{tabular}

Note: data presented $N$ (\%). $P$ value significant at 0.05 and 0.01 level using multinomial logistic regression and chi-square test. Odds ratio (OR) and $P$ value adjusted for adjustment of multiple comparisons. Significant values are in bold text. * Reference. 
TABLE 3: Comparison of BTMs levels according to PTHR1 rs1138518 genotypes in the study groups.

\begin{tabular}{|c|c|c|c|c|}
\hline \multirow{2}{*}{ Parameters } & \multicolumn{2}{|c|}{ PTHR1 rs1138518 } & \multirow{2}{*}{$P$ values } & \multirow{2}{*}{$P$ values* } \\
\hline & CG & $\mathrm{PMO}$ & & \\
\hline \multicolumn{5}{|l|}{ Genotype T/T } \\
\hline 25(OH)D (nmol/l) & $58.2(39.6-81.0)$ & $81.2(60.8-101.7)$ & 0.02 & 0.04 \\
\hline PTH (pg/ml) & $12.1(6.5-26.1)$ & $15.2(6.7-48.1)$ & 0.67 & 0.74 \\
\hline OPG (pg/ml) & $866.3(621.2-1081.7)$ & $744.6(558.4-979.4)$ & 0.36 & 0.65 \\
\hline OPN (pg/ml) & $2505.2(1334.6-3121.7)$ & $3181.5(1825.4-4863.1)$ & 0.18 & 0.28 \\
\hline RANKL (pg/ml) & $40.6(23.3-68.3)$ & $32.8(25.4-77.6)$ & 0.96 & 0.96 \\
\hline$\beta$-CTx $(\mathrm{ng} / \mathrm{ml})$ & $0.1(0.0-0.1)$ & $0.1(0.0-0.1)$ & 0.46 & 0.58 \\
\hline Osteocalcin (ng/ml) & $5.8(2.9-14.5)$ & $7.1(1.8-13.5)$ & 0.036 & 0.09 \\
\hline \multicolumn{5}{|l|}{ Genotype C/T } \\
\hline 25(OH)D (nmol/l) & $66.4(43.5-87.8)$ & $59.9(36.7-92.4)$ & 0.51 & 0.048 \\
\hline PTH (pg/ml) & $12.2(7.9-17.8)$ & $17.8(10.6-69.6)$ & 0.016 & 0.10 \\
\hline OPG $(\mathrm{pg} / \mathrm{ml})$ & $719.8(471.5-887.6)$ & $854.9(609.3-1056.2)$ & 0.07 & 0.54 \\
\hline OPN (pg/ml) & $2298.0(1397.7-2952.2)$ & $2651.6(1706.7-3986.1)$ & 0.12 & 0.66 \\
\hline RANKL (pg/ml) & $32.0(13.4-65.5)$ & $29.0(21.6-48.2)$ & 0.84 & 0.87 \\
\hline$\beta$-CTx (ng/ml) & $0.1(0.0-0.1)$ & $0.1(0.1-0.2)$ & 0.70 & 0.80 \\
\hline Osteocalcin (ng/ml) & $8.6(3.2-12.5)$ & $10.7(4.8-15.3)$ & 0.023 & 0.23 \\
\hline \multicolumn{5}{|l|}{ Genotype C/C } \\
\hline $25(\mathrm{OH}) \mathrm{D}(\mathrm{nmol} / \mathrm{l})$ & $60.6(36.6-82.6)$ & $65.9(41.8-87.1)$ & 0.24 & 0.52 \\
\hline PTH (pg/ml) & $12.3(8.4-26.7)$ & $13.6(6.9-27.5)$ & 0.738 & 0.55 \\
\hline OPG (pg/ml) & $752.1(513.6-1168.1)$ & $826.7(641.3-1227.7)$ & 0.252 & 0.44 \\
\hline OPN (pg/ml) & $2356.5(804.5-3482.8)$ & $1812.1(689.1-3424.8)$ & 0.458 & 0.67 \\
\hline RANKL (pg/ml) & $33.9(18.4-62.2)$ & $27.9(21.2-48.2)$ & 0.535 & 0.40 \\
\hline$\beta$-CTx $(\mathrm{ng} / \mathrm{ml})$ & $0.1(0.0-0.1)$ & $0.1(0.0-0.1)$ & 0.690 & 0.48 \\
\hline Osteocalcin (ng/ml) & $9.4(3.4-13.6)$ & $8.0(3.5-12.9)$ & 0.699 & 0.75 \\
\hline
\end{tabular}

Note: data presented as mean $\pm \mathrm{SD}$ for normal variables while median $(\mathrm{Q} 1-\mathrm{Q} 3)$ for nonnormal variables; $P<0.05$ considered significant. ${ }^{*}$ Adjusted $P$ value for adjustment for multiple comparisons.

TABLE 4: Comparative analysis of inflammatory marker levels according to PTHR1 rs1138518 genotypes in the study groups.

\begin{tabular}{|c|c|c|c|c|}
\hline \multirow{2}{*}{ Parameters } & \multicolumn{2}{|c|}{ PTHR1 rs1138518 } & \multirow{2}{*}{$P$ values } & \multirow{2}{*}{$P$ values } \\
\hline & CG & $\mathrm{PMO}$ & & \\
\hline \multicolumn{5}{|l|}{ Genotype T/T } \\
\hline $\mathrm{IL}-4(\mathrm{pg} / \mathrm{ml})$ & $5.4(3.5-7.7)$ & $3.8(3.0-7.4)$ & 0.44 & 0.51 \\
\hline $\mathrm{IL}-1 \beta(\mathrm{pg} / \mathrm{ml})$ & $1.6(0.3-2.7)$ & $0.4(0.3-1.6)$ & 0.16 & 0.15 \\
\hline Leptin $(\mathrm{pg} / \mathrm{ml})$ & $22697.3(11742.5-42916.3)$ & $28803.4(12919.2-37878.6)$ & 0.84 & 0.29 \\
\hline TGF- $\beta(\mathrm{pg} / \mathrm{ml})$ & 40749.5 (37204.7-48681.4) & $43097.6(40137.4-51499.3)$ & 0.62 & 0.55 \\
\hline \multicolumn{5}{|l|}{ Genotype C/T } \\
\hline $\mathrm{IL}-4(\mathrm{pg} / \mathrm{ml})$ & $8.2(4.2-10.6)$ & $4.1(2.5-9.0)$ & 0.10 & 0.26 \\
\hline $\mathrm{IL}-1 \beta(\mathrm{pg} / \mathrm{ml})$ & $1.8(0.5-2.7)$ & $2.0(0.3-2.8)$ & 0.69 & 0.93 \\
\hline Leptin $(\mathrm{pg} / \mathrm{ml})$ & $14532.2(4761.6-27012.4)$ & $20484.0(10396.4-29426.2)$ & 0.14 & 0.27 \\
\hline TGF- $\beta(\mathrm{pg} / \mathrm{ml})$ & $37710.2(29447.5-52241.4)$ & $34811.5(17464.4-46481.6)$ & 0.31 & 0.13 \\
\hline \multicolumn{5}{|l|}{ Genotype $\mathrm{C} / \mathrm{C}$} \\
\hline $\mathrm{IL}-4(\mathrm{pg} / \mathrm{ml})$ & $7.1(3.7-10.7)$ & $4.6(2.5-9.3)$ & 0.6 & 0.06 \\
\hline $\mathrm{IL}-1 \beta(\mathrm{pg} / \mathrm{ml})$ & $1.8(0.4-2.9)$ & $1.6(0.3-2.7)$ & 0.22 & 0.09 \\
\hline Leptin (pg/ml) & $14405.6(1020.8-33059.9)$ & $18808.1(3756.0-31273.4)$ & 0.71 & 0.39 \\
\hline TGF- $\beta(\mathrm{pg} / \mathrm{ml})$ & $42041.5(26232.0-54136.5)$ & $33770.1(15509.4-50533.2)$ & 0.08 & 0.09 \\
\hline
\end{tabular}

Note: data presented as mean \pm SD for normal variables while median (Q1-Q3) for nonnormal variables; $P<0.05$ considered significant. ${ }^{*}$ Adjusted $P$ value for adjustment for multiple comparisons. 
health. These two hormones form a tightly controlled feedback cycle in which the production of $25(\mathrm{OH}) \mathrm{D}$ is stimulated by PTH, whereas $25(\mathrm{OH}) \mathrm{D}$ exerts negative feedback on PTH secretion [27]. This inverse correlation between $25(\mathrm{OH}) \mathrm{D}$ and PTH has been reported in many other studies [28-30].

The PTH-PTHR two-step binding mechanism between PTH and PTHRs helps stabilize the conformational changes implicated by the receptor activation and G-protein [31]. PTHR mediates bone homeostasis and systemic Ca2+ levels. The ligation mainly mediates PTHR activation to endocrine PTH, which triggers internalization and can stimulate sustained endosomal signaling $[32,33]$. PTHR can also be activated by the paracrine ligand PTHrP to regulate biochemical processes in bone and other tissues [34].

We acknowledge that there are some limitations to our study. The subject selection involved only postmenopausal Arab women, and therefore, our findings may have limited relevance for different populations. As such, the results could differ using other ethnic groups. Furthermore, the sample size in the present study was small, which could affect applying this finding to a more significant cohort. No association of PTH or PTHR2 polymorphism was noted in the subjects. We also did not measure circulating $\mathrm{Ca} 2+$ levels in subjects of this study as a key component in the $\mathrm{PTH} / 25(\mathrm{OH}) \mathrm{D}$ feedback loop, and this data could be further investigated. Despite these limitations, to the best of our knowledge, this study is the first to evaluate the relationships between PTHR1 polymorphisms and bone turnover markers in PMO. Unlike earlier SNP-based studies, which mostly focused on the correlation between the genetic polymorphisms of bone regulation and osteoporosis phenotypes, we investigated the possible effects of susceptibility SNPs on serum levels of BTMs.

\section{Conclusions}

Our study is the first to identify that PTHR1 rs1138518 is substantially associated with PMO among Saudi Arabian postmenopausal women. The $\mathrm{C} / \mathrm{T}$ heterozygote genotype was found to impact the PTH-25(OH)D feedback significantly. The $\mathrm{T} / \mathrm{T}$ genotype plays a role in maintaining high 25(OH)D levels in PMO patients. Therefore, PTHR1 rs1138518 could represent an integrative biomarker for 25 $(\mathrm{OH}) \mathrm{D}$ and PTH levels in PMO Arab patients. Further molecular functional mechanism studies of the role of PTHR1 rs1138518 in PMO regulation are necessary to clarify this correlation.

\section{Data Availability}

The data is available from the corresponding author on reasonable request.

\section{Disclosure}

The funders had no role in the design of the study; in the collection, analyses, or interpretation of data; in the writing of the manuscript; or in the decision to publish the results.
The present study has been previously presented as poster abstract in the 2021 "World Congress on Osteoporosis, Osteoarthritis and Musculoskeletal Diseases" (https://www.wcoiof-esceo.org/sites/wco_22/pdf/WCO21-AbstractBook.pdf).

\section{Conflicts of Interest}

The authors declare no conflict of interest.

\section{Authors' Contributions}

Saba Abdi and Abeer Abdulaziz Almiman contributed equally to this work.

\section{Acknowledgments}

This project was funded by the National Plan for Science, Technology and Innovation (MAARIFAH), King Abdulaziz City for Science and Technology, Kingdom of Saudi Arabia, Award Number (12-BIO2646-02).

\section{References}

[1] S. Abdi, R. A. Binbaz, A. K. Mohammed et al., "Association of RANKL and OPG gene polymorphism in Arab women with and without osteoporosis," Genes, vol. 12, no. 2, p. 200, 2021.

[2] S. Zhou, Z. Tao, Y. Zhu, and L. Tao, "Mapping theme trends and recognizing hot spots in postmenopausal osteoporosis research: a bibliometric analysis," PeerJ, vol. 7, pp. e8145e8145, 2019.

[3] S. Abdi, I. Bukhari, M. G. Ansari et al., "Association of polymorphisms in RANK and RANKL genes with osteopenia in Arab postmenopausal women," Disease Markers, vol. 2020, Article ID 1285216, 2020.

[4] M. S. M. Ardawi, A. A. Maimany, T. M. Bahksh, H. A. N. Nasrat, W. A. Milaat, and R. M. Al-Raddadi, "Bone mineral density of the spine and femur in healthy Saudis," Osteoporosis International, vol. 16, no. 1, pp. 43-55, 2005.

[5] M. G. A. Ansari, S. D. Hussain, K. A. Wani et al., "Influence of bone mineral density in circulating adipokines among postmenopausal Arab women," Saudi Journal of Biological Sciences, vol. 27, no. 1, pp. 374-379, 2020.

[6] K. Wani, S. M. Yakout, M. G. A. Ansari et al., "Metabolic syndrome in Arab adults with low bone mineral density," Nutrients, vol. 11, no. 6, p. 1405, 2019.

[7] R. Civitelli and K. Ziambaras, "Calcium and phosphate homeostasis: concerted interplay of new regulators," Journal of Endocrinological Investigation, vol. 34, 7 Supplement, pp. 3-7, 2011.

[8] M. Khan and S. Sharma, "Physiology, Parathyroid Hormone (PTH)," in StatPearls, StatPearls PublishingStatPearls Publishing LLC, Treasure Island (FL), 2020.

[9] R. W. Cheloha, S. H. Gellman, J. P. Vilardaga, and T. J. Gardella, "PTH receptor-1 signalling-mechanistic insights and therapeutic prospects," Nature Reviews. Endocrinology, vol. 11, no. 12, pp. 712-724, 2015.

[10] A. J. Venkatakrishnan, X. Deupi, G. Lebon, C. G. Tate, G. F. Schertler, and M. M. Babu, "Molecular signatures of Gprotein-coupled receptors," Nature, vol. 494, no. 7436, pp. 185-194, 2013. 
[11] I. Sutkeviciute, L. J. Clark, A. D. White, T. J. Gardella, and J. P. Vilardaga, "PTH/PTHrP receptor signaling, allostery, and structures," Trends in Endocrinology and Metabolism, vol. 30, no. 11, pp. 860-874, 2019.

[12] A. Maeda, M. Okazaki, D. M. Baron et al., "Critical role of parathyroid hormone (PTH) receptor-1 phosphorylation in regulating acute responses to $\mathrm{PTH}$," Proceedings of the National Academy of Sciences of the United States of America, vol. 110, no. 15, pp. 5864-5869, 2013.

[13] A. C. Karaplis and D. Goltzman, "PTH and PTHrP effects on the skeleton," Reviews in Endocrine \& Metabolic Disorders, vol. 1, no. 4, pp. 331-341, 2000.

[14] M. E. Cupp, S. K. Nayak, A. S. Adem, and W. J. Thomsen, "Parathyroid hormone (PTH) and PTH-related peptide domains contributing to activation of different PTH receptor-mediated signaling pathways," The Journal of Pharmacology and Experimental Therapeutics, vol. 345, no. 3, pp. 404-418, 2013.

[15] B. N. Bohinc and D. Gesty-Palmer, "Biased agonism at the parathyroid hormone receptor: a demonstration of functional selectivity in bone metabolism," Mini Reviews in Medicinal Chemistry, vol. 12, no. 9, pp. 856-865, 2012.

[16] N. M. Al-Daghri, O. S. Al-Attas, S. Krishnaswamy et al., "Association between promoter region genetic variants of PTH SNPs and serum 25(OH)-vitamin D level," International Journal of Clinical and Experimental Pathology, vol. 8, no. 7, pp. 8463-8471, 2015.

[17] N. M. Al-Daghri, S. M. Yakout, M. G. Ansari, S. D. Hussain, K. A. Wani, and S. Sabico, "Vitamin D metabolites and sex steroid indices in postmenopausal women with and without low bone mass," Metabolites, vol. 11, no. 2, p. 86, 2021.

[18] Y. Al-Saleh, R. Sulimani, S. Sabico et al., "2015 guidelines for osteoporosis in Saudi Arabia: recommendations from the Saudi Osteoporosis Society," Annals of Saudi Medicine, vol. 35, no. 1, pp. 1-12, 2015.

[19] Y. Al-Saleh, N. M. Al-Daghri, S. Sabico et al., "Diagnosis and management of osteoporosis in postmenopausal women in Gulf Cooperation Council (GCC) countries: consensus statement of the GCC countries' osteoporosis societies under the auspices of the European Society for Clinical and Economic Aspects of Osteoporosis and Osteoarthritis (ESCEO)," Archives of Osteoporosis, vol. 15, no. 1, p. 109, 2020.

[20] R. S. Albassam, S. Sabico, A. M. Alnaami et al., "Bone metabolism markers are associated with neck circumference in adult Arab women," Osteoporosis International, vol. 30, no. 4, pp. 845-852, 2019.

[21] C. Vilariño-Güell, L. J. Miles, E. L. Duncan et al., "PTHR1 polymorphisms influence BMD variation through effects on the growing skeleton," Calcified Tissue International, vol. 81, no. 4, pp. 270-278, 2007.

[22] E. L. Duncan, M. A. Brown, J. Sinsheimer et al., "Suggestive linkage of the parathyroid receptor type 1 to osteoporosis," Journal of Bone and Mineral Research, vol. 14, no. 12, pp. 1993-1999, 1999.

[23] F. Wynne, F. J. Drummond, M. Daly et al., "Suggestive linkage of 2p22-25 and 11q12-13 with low bone mineral density at the lumbar spine in the Irish population," Calcified Tissue International, vol. 72, no. 6, pp. 651-658, 2003.

[24] M. Minagawa, T. Yasuda, T. Watanabe et al., "Association between AAAG repeat polymorphism in the P3 promoter of the human parathyroid hormone (PTH)/PTH-related peptide receptor gene and adult height, urinary pyridinoline excretion, and promoter activity," The Journal of Clinical Endocrinology and Metabolism, vol. 87, no. 4, pp. 1791-1796, 2002.

[25] Y. Y. Zhang, P. Y. Liu, Y. Lu et al., "Tests of linkage and association of PTH/PTHrP receptor type 1 gene with bone mineral density and height in Caucasians," Journal of Bone and Mineral Metabolism, vol. 24, no. 1, pp. 36-41, 2006.

[26] S. Noordin and J. Glowacki, "Parathyroid hormone and its receptor gene polymorphisms: implications in osteoporosis and in fracture healing," Rheumatology International, vol. 36, no. 1, pp. 1-6, 2016.

[27] P. Lips, "Vitamin D physiology," Progress in Biophysics and Molecular Biology, vol. 92, no. 1, pp. 4-8, 2006.

[28] P. Quaggiotto, H. Tran, and M. Bhanugopan, "Vitamin D deficiency remains prevalent despite increased laboratory testing in New South Wales, Australia," Singapore Medical Journal, vol. 55, no. 5, pp. 271-280, 2014.

[29] A. Lejnieks, A. Slaidina, A. Zvaigzne et al., "Vitamin D status and its seasonal variations and association with parathyroid hormone concentration in healthy women in Riga," Medicina, vol. 49, no. 7, pp. 329-334, 2013.

[30] N. Tsugawa, K. Uenishi, H. Ishida et al., "Association between vitamin D status and serum parathyroid hormone concentration and calcaneal stiffness in Japanese adolescents: sex differences in susceptibility to vitamin D deficiency," Journal of Bone and Mineral Metabolism, vol. 34, no. 4, pp. 464-474, 2016.

[31] M. Castro, V. O. Nikolaev, D. Palm, M. J. Lohse, and J.P. Vilardaga, "Turn-on switch in parathyroid hormone receptor by a two-step parathyroid hormone binding mechanism," Proceedings of the National Academy of Sciences of the United States of America., vol. 102, no. 44, pp. 16084-16089, 2005.

[32] J.-P. Vilardaga, F. G. Jean-Alphonse, and T. J. Gardella, "Endosomal generation of cAMP in GPCR signaling," Nature Chemical Biology, vol. 10, no. 9, pp. 700-706, 2014.

[33] H. Chen, X. Han, Y. Cui, Y. Ye, Y. Purrunsing, and N. Wang, "Parathyroid hormone fragments: new targets for the diagnosis and treatment of chronic kidney disease-mineral and bone disorder," BioMed Research International, vol. 2018, Article ID 9619253, 2018.

[34] J. P. Vilardaga, G. Romero, P. A. Friedman, and T. J. Gardella, "Molecular basis of parathyroid hormone receptor signaling and trafficking: a family B GPCR paradigm," Cellular and Molecular Life Sciences, vol. 68, no. 1, pp. 1-13, 2011. 